\title{
Anti-Pneumocystis carinii and antiplasmodial activities of primaquine-derived imidazolidin-4-ones
}

\author{
Nuno Vale, ${ }^{\text {a }}$ Margaret S. Collins, ${ }^{\text {c,d }}$ Jiri Gut, ${ }^{\text {e }}$ Ricardo Ferraz, ${ }^{\mathrm{a}, \mathrm{b}}$ \\ Philip J. Rosenthal, ${ }^{\text {e }}$ Melanie T. Cushion, ${ }^{\text {c,d }}$ Rui Moreira ${ }^{\mathrm{f}}$ and Paula Gomes ${ }^{\mathrm{a}, *}$ \\ ${ }^{a}$ CIQUP_Centro de Investigação em Química da Universidade do Porto, Departamento de Química, Faculdade de Ciências, \\ Universidade do Porto, P-4169-007 Porto, Portugal \\ ${ }^{\mathrm{b}}$ Escola Superior de Tecnologias de Saúde do Porto, Instituto Politécnico do Porto, P-4000-294 Porto, Portugal \\ ${ }^{\mathrm{c}}$ Division of Infectious Diseases, Department of Internal Medicine, University of Cincinnati, OH 45267-0560, USA \\ ${ }^{\mathrm{d}}$ Research Services, Veterans Affairs Medical Center, Cincinnati, OH 45220, USA \\ e Department of Medicine, San Francisco General Hospital, University of California, San Francisco, CA 94143-0811, USA

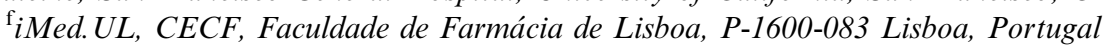

Received 11 October 2007; revised 22 November 2007; accepted 27 November 2007

Available online 3 December 2007

\begin{abstract}
A series of primaquine-derived imidazolidin-4-ones were screened for their in vitro activity against Pneumocystis carinii and Plasmodium falciparum W2 strain. Most compounds were active against $P$. carinii above $10 \mu \mathrm{g} / \mathrm{mL}$ and displayed slight to marked activity. The imidazolidin-4-ones most active against $P$. carinii were also those most active antiplasmodial agents, in the $\mu \mathrm{M}$ range. One of the tested imidazolidin-4-ones was slightly more active than the parent primaquine and may represent a lead compound for the development of novel anti- $P$. carinii 8-aminoquinolines with increased stability and resistance to metabolic inactivation.
\end{abstract}

(C) 2007 Elsevier Ltd. All rights reserved.

Pneumocystis pneumonia (PCP) is a fungal opportunistic infection caused by Pneumocystis jirovecii (formerly Pneumocystis carinii $^{1,2}$ ) and is one the most frequent causes of mortality in patients with acquired immunodeficiency syndrome (AIDS). ${ }^{3,4}$ PCP also affects other immunocompromised individuals such as those undergoing cancer therapy and organ and bone marrow transplants. ${ }^{5}$ Despite the decline in incidence of PCP in AIDS patients as a consequence of the highly active antiretroviral therapy (HAART), PCP remains the most prevalent opportunistic infection found in individuals infected with the human immunodeficiency virus (HIV). ${ }^{67} P$. jirovecii is insensitive to standard antifungal therapy and thus, the antifolate combination of trimethoprim and sulfamethoxazole (TMP-SMX) has been used for both its prophylaxis and treatment of PCP. ${ }^{8,9}$ However, emerging resistance and allergic reactions against the sulfa component often lead to the alternative use

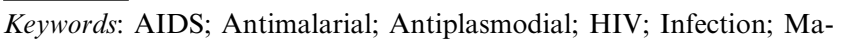
laria; Plasmodium falciparum; Pneumocystis carinii; Primaquine.

* Corresponding author. Tel.: +351 22040 2563; fax: +351 22040 2659; e-mail: pgomes@fc.up.pt of pentamidine and atovaquone. ${ }^{8-10}$ Unfortunately, pentamidine is ineffective orally and toxic effects have been reported for this drug, ${ }^{8}$ while failure of atovaquone treatment in AIDS patients with PCP is a major concern. ${ }^{11}$

Primaquine (1a), an 8-aminoquinoline antimalarial, is effective against mild to moderate PCP and is co-administered with clindamycin to AIDS patients with comparable efficacy to TMP-SMX. ${ }^{9}$ Optimization of 8-aminoquinolines to improve their antimalarial activity as well as to reduce adverse effects such as neutropenia and methemogobinemia also resulted in an improvement of activity against PCP. ${ }^{8,12,13}$ This observation led to the suggestion that such synchrony between the structure-activity relationships (SARs) for the protozoal and fungal diseases could be useful to develop novel 8aminoquinolines with improved efficacy against PCP (e.g., $\mathbf{1 b}, \mathbf{c}) .{ }^{14}$ We recently reported that imidazolidin4-one derivatives of primaquine, 2 (Scheme 1), exert potent gametocytocidal activity against Plasmodium berghei infection developed in BalbC mice. ${ }^{15}$ Such promising results encouraged us to go on further investigating the in vitro anti- $P$. carinii activities of com- 


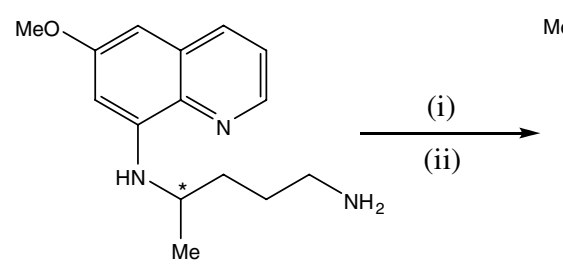

$1 \mathbf{a}$<smiles>CCCCCNC(=O)C(N)Nc1cc(OC)cc2cccnc12</smiles>

3<smiles>[R]C1(P)N[C@H](C)C(=O)N1CCCC([CH])Nc1cc(OC)cc2cccnc12</smiles>

Scheme 1. Reagents and conditions: (i) $N^{\alpha}$-Boc-protected amino acid, diisopropyl- or dicyclohexyl-carbodiimide, 1-hydroxybenzotriazole, dichloromethane; rt, $120 \mathrm{~h}$; (ii) a-neat TFA, rt, $2 \mathrm{~h}$; b-30\% aq $\mathrm{Na}_{2} \mathrm{CO}_{3}+$ extraction with chloroform; (iii) molecular sieves, refluxing methanol, 72 h. $^{16-18}$

pounds 2, which are now herein reported. Since most of the SARs available for 8-aminoquinolines refer to liver or blood schizontocidal activities, we also decided to screen the activity of primaquine imidazolidin-4-ones, 2, against the chloroquine-resistant Plasmodium falciparum strain W2.<smiles>[Y]c1ccnc2c(NC([CH])CCCN)cc(OC)c([Y])c12</smiles>

Imidazolidin-4-ones, 2, were obtained from condensation of racemic primaquine-derived $\alpha$-aminoamides, $\mathbf{3}$, with symmetrical ketones and $o$-methylbenzaldehyde (Scheme 1) ${ }^{16,17}$ Compounds 2 resulting from the reaction of 3 with propanone and cyclic ketones were isolated as mixtures of two diastereomers (enantiomers, in the case of glycine derivatives $\mathbf{2 a}, \mathbf{i}$ ). In contrast, three chromatographic distinct fractions were obtained for the $(S)$-Phe-derived imidazolidin-4-one $\mathbf{2 m}$, synthesized by reacting the $(S)$-Phe derivative $\mathbf{3}$ and $o$-methylbenzaldehyde: two were isolated as pure diastereomers $\left(\mathbf{2 m}_{1}\right.$ and $\mathbf{2} \mathbf{m}_{2}$ ) and one as the unresolved diastereomeric mixture of the remaining two $\left(\mathbf{2 m}_{3}+\mathbf{2 m}_{4}\right) \cdot{ }^{16,17}$
Imidazolidin-4-ones $\mathbf{2 a}-\mathbf{m}$ were evaluated ${ }^{19}$ against $P$. carinii in an ATP measurement assay based on a luciferin-luciferase mediated reaction ${ }^{20}$ and against chloroquine-resistant $P$. falciparum strain W2; the results obtained are given in Table 1.

Inspection of Table 1 shows that imidazolidin-4-ones 2a-m exhibit a twofold variation in anti- $P$. carinii activities, ranging from practically insignificant (2b) to marked (2j), in this case even slightly higher (in $\mu \mathrm{M}$ ) than that of the parent PQ (1a). Considering the effect of substituents $\mathrm{R}^{2}$ and $\mathrm{R}^{3}$ at imidazolidin-4-one $\mathrm{C}-2$ on the activity, those compounds derived from propanone (2a-d) are among the less active of the set, whereas the top-three compounds are those derived from cycloheptanone $(\mathbf{2 g}, \mathbf{2 j}-\mathbf{k})$. The substituents $\mathrm{R}^{2}$ and $\mathrm{R}^{3}$ brought by the carbonyl reactant seem to play a major role in the modulation of the anti- $P$. carinii activity of compounds $\mathbf{2}$, with larger and more hydrophobic groups being apparently preferable. This is illustrated by analysis of the $(S)$-Val series, where the activity increases $\mathbf{2 c}<\mathbf{2 e} \cong \mathbf{2 f}<\mathbf{2 g}$. Imidazolidin-4-ones 2 are hydrolyzed very slowly to the corresponding amino acid derivatives, 3, in $\mathrm{pH} 7.4$ buffer with half-lives ranging from ca. 10-30 days in $\mathrm{pH} 7.4$ buffer at $37^{\circ} \mathrm{C} .{ }^{15}$ In the present study, we assessed the stability of compound $\mathbf{2 g}$, which presents a half-life higher than 10 days in the same reaction media. This result is consistent with the observation that imidazolidin-4-ones 2 containing a seven-membered ring and derived from amino acids containing large $\alpha$-substituents are stable in aqueous solutions, ${ }^{15}$ thus suggesting that $\mathbf{2 g}$ is active against $P$. carinii per se. Finally, comparison of data from $\mathbf{2} \mathbf{m}_{1}, \mathbf{2} \mathbf{m}_{2}$ and $\mathbf{2 m}_{3}+\mathbf{2} \mathbf{m}_{4}$ shows that (i) when $\mathrm{R}^{2}=\mathrm{H}$, the activities are identical to those 
Table 1. Anti-P. carinii activity and cytotoxicity of PQ (1) and its imidazolidin-4-one derivatives $\mathbf{2} \mathbf{a}-\mathbf{m}^{\mathrm{a}}$

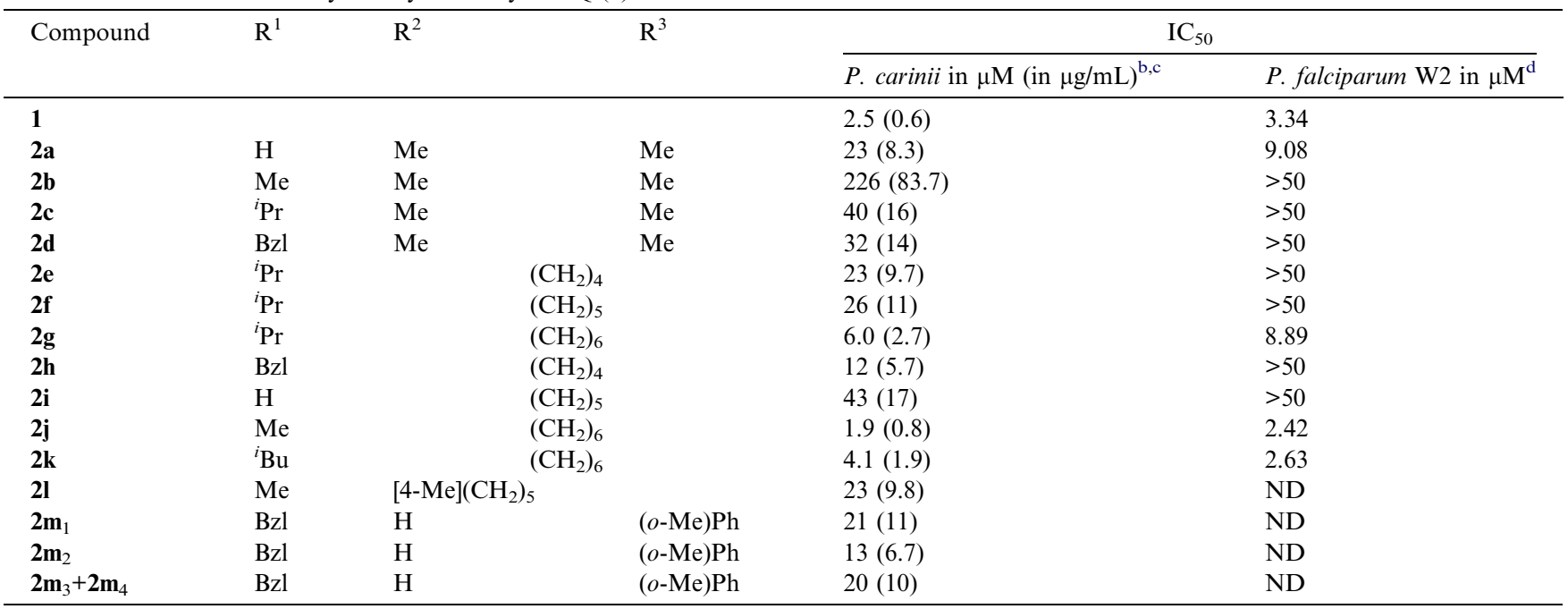

${ }^{a}$ All biological activities resulted from the average of at least three determinations.

${ }^{\mathrm{b}}$ Drug activity scale: highly active, $<0.01 \mu \mathrm{g} / \mathrm{mL}$; very marked, $<0.1 \mu \mathrm{g} / \mathrm{mL}$; marked, $0.1-0.9 \mu \mathrm{g} / \mathrm{mL}$; moderate, $1.0-9.9 \mu \mathrm{g} / \mathrm{mL} ;$ slight, $10.0-49.9 \mu \mathrm{g} /$ $\mathrm{mL} .^{21}$

${ }^{\mathrm{c}} 72$-h incubation assays.

${ }^{\mathrm{d}}$ Assays of parasite development were performed as described earlier. ${ }^{22}$

derived from propanone and cyclopentanone (e.g., $2 \mathbf{m}$ vs $\mathbf{2 d}$ and $\mathbf{2 h}$ ) and (ii) there are no marked differences between diastereomers, even though $\mathbf{2} \mathbf{m}_{2}$ is slightly more active than $\mathbf{2} \mathbf{m}_{1}$.

When analyzing the effect of the amino acid side chain, that is, the $\mathrm{R}^{1}$ substituents at the $\mathrm{C}-5$ position of imidazolidin-4-ones 2 on the anti- $P$. carinii activity, the results suggest that $\mathrm{R}^{1}$ has not a well-defined or marked influence on the anti- $P$. carinii activity. If the three most active compounds $(\mathbf{2 g}, \mathbf{2} \mathbf{j}$, and $\mathbf{2 k})$ are considered, the $\mathrm{IC}_{50}$ values follow the order $\mathbf{2 g}$, $(S)$-Val $>\mathbf{2} \mathbf{k},(S)$-Leu $>\mathbf{2} \mathbf{j}$, (S)-Ala, but differ at the most by 3 -fold (2g vs $2 \mathbf{j})$. On the other hand, if we consider the propanone-derived subset 2a-d, the highest $\mathrm{IC}_{50}$ is displayed by the $(S)$ Ala derivative (2b), differing from the second highest value (for 2c) by as much as 55-fold. Interestingly, the anti- $P$. carinii SAR herein described is not entirely coincidental with that for the gametocytocidal activity of $\mathbf{2}$, as in this case small amino acid side chains significantly improved the gametocytocidal activity of those compounds against $P$. berghei, whereas bulky/hydrophobic amino acids had detrimental effects. ${ }^{15}$ In contrast, the reported influence of $\mathrm{R}^{2}$ and $\mathrm{R}^{3}$ on the gametocytocidal activity of compounds $\mathbf{2}$ is not marked, ${ }^{15}$ which suggests that the stereoelectronic requisites for the fine-tuning of 2 as gametocytocidals do not exactly match those for optimal anti- $P$. carinii activity. However, if the antiplasmodial activities of $\mathbf{2}$ against the chloroquine-resistant $P$. falciparum strain W2 are considered (Table 1), one observes that (i) the most active antiplasmodial agents are also those most active against $P$. carinii (i.e., $\mathbf{2 g}$, $\mathbf{2 j - k}$ ) and (ii) excepting propanone derivative $\mathbf{2 a}$, all remaining compounds $\mathbf{2}$ are inactive against $P$. falciparum in this screen. Thus, the presence of larger and more hydrophobic groups, such as a seven-membered ring, at $\mathrm{C}-2$ of the imidazolidin-4-one moiety is also a major requirement for antiplasmodial activity.
In conclusion, the reported imidazolidin-4-ones prepared from amino acid derivatives of primaquine exhibit potent activity against $P$. carinii. The present screening of compounds $\mathbf{2}$ allowed the selection of $\mathbf{2} \mathbf{j}$ as a potential lead structure for the future development of effective anti-PCP agents. Although $P$. jirovecii is the causative agent of PCP in humans, in vitro drug screening systems using organisms derived from rodent models have provided investigators with the only method to identify and screen new candidate anti-Pneumocystis compounds. However, in vivo studies have shown that there is a high degree of correlation between animal models and human beings. ${ }^{23}$ In general, those derivatives 2 containing larger and more hydrophobic $\mathrm{R}^{2}$ and $\mathrm{R}^{3}$ substituents at C-2 are superior to those containing small substituents. Another interesting finding is that the imidazolidin-4-one weakly basic amino group (p $K_{a}$ ca. 4$)$ is not detrimental to the anti- $P$. carinii activity, thus suggesting that the strongly basic primary amino group present in primaquine and other 8-aminoquinoline side chains is not a major requirement for anti-PCP activity. Taking into account that acylation of primary amino group blocks cytochrome P450- and MAO-catalyzed oxidative deamination of primaquine, ${ }^{24}$ imidazolidin-4ones 2 might offer a useful approach to overcome metabolic inactivation of primaquine into carboxyprimaquine. Finally, the antiplasmodial activity seems to be a useful indicator of the anti- $P$. carinii activity.

\section{Acknowledgments}

N.V. thanks Fundação para a Ciência e Tecnologia (FCT, Portugal) for Ph.D. Grant SFRH/BD/17754/ 2004. P.G. and R.M. thank FCT for financial support to CIQUP and CECF, respectively. P.J.R. was supported by grants from the National Institutes of Health and Medicines for Malaria Venture. M.T.C. and M.S.C. 
acknowledge the support of Public Health Service Grant N01 AI75319 from the National Institutes of Allergy and Infectious Diseases and the Medical Research Service Department of the Veterans Affairs, USA.

\section{References and notes}

1. Redhead, S. A.; Cushion, M. T.; Frenkel, J. K.; Stringer, J. R. J. Eukaryot. Microbiol. 2006, 53, 2.

2. Hawksworth, D. L. Lancet Infect. Dis. 2007, 7, 3.

3. Thomas, C. F., Jr.; Limper, A. H. New Engl. J. Med. 2004, 350, 2487.

4. Peterson, J. C.; Cushion, M. T. Curr. Opin. Microbiol. 2005, 8, 393.

5. Fishman, J. A. Antimicrob. Agents Chemother. 1998, 42, 995.

6. Barry, S. M.; Johnson, M. A. HIV Med. 2001, 2, 123.

7. Morris, A.; Lundgren, J. D.; Masur, H.; Walzer, P. D.; Hanson, D. L.; Frederick, T.; Huang, L.; Beard, C. B.; Kaplan, J. E. Emerg. Infect. Dis. 2004, 10, 1713.

8. Queener, S. F. J. Med. Chem. 1995, 38, 4739.

9. Fishman, J. A. Antimicrob. Agents Chemother. 1998, 42, 1309.

10. Chan, C.; Montaner, J.; Lefebvre, E. A.; Morey, G.; Dohn, M.; McIvor, R. A.; Scott, J.; Marina, R.; Caldwell, P. J. Infect. Dis. 1999, 180, 369.

11. Kessl, J. J.; Hill, P.; Lange, B. B.; Meshnick, S. R.; Meunier, B.; Trumpower, B. L. J. Biol. Chem 2004, 279, 2817, and references cited herein.

12. Bartlett, S. R.; Queener, S. F.; Tidwell, R. R.; Milhouse, W. K.; Berman, J. D.; Ellis, W. Y.; Smith, J. W. Antimicrob. Agents Chemother. 1991, 35, 277.

13. Queener, S. F.; Bartlett, M. S.; Nasr, M.; Smith, J. W. Antimicrob. Agents Chemother. 1993, 37, 2166.

14. Goodwin, T. E.; Boylan, C. J.; Current, W. L.; Byrd, J. C.; Fuller, D. A.; Green, J. L.; Larocca, C. D.; Raney, K. D.; Ross, A. S.; Tucker, W. A. Bioorg. Med. Chem. Lett. 2000, 10, 2205.

15. Araújo, M. J.; Bom, J.; Capela, R.; Casimiro, C.; Chambel, P.; Gomes, P.; Iley, J.; Lopes, F.; Morais, J.; Moreira, R.; de Oliveira, E.; do Rosário, V.; Vale, N. J. Med. Chem. 2005, 48, 888.

16. Gomes, P.; Araújo, M. J.; Rodrigues, M.; Vale, N.; Azevedo, Z.; Iley, J.; Chambel, P.; Morais, J.; Moreira, R. Tetrahedron 2004, 60, 5551.

17. Ferraz, R.; Gomes, J. R. B.; de Oliveira, E.; Moreira, R.; Gomes, P. J. Org. Chem. 2007, 72, 4189.

18. Compounds 2 can be synthesized in good yields from the corresponding amino acid derivatives AA-PQ, 3, by refluxing with an excess of ketone or aldehyde in methanol in the presence of triethylamine and $4 \AA$ molecular sieves.
As an example, compound $\mathbf{2} \mathbf{g}$ was prepared by refluxing 3g $\left(\mathrm{R}^{1}={ }^{i} \mathrm{Pr}\right.$, $1 \mathrm{~mol}$ equiv) with cycloheptanone $(2 \mathrm{~mol}$ equiv) in dry methanol for $72 \mathrm{~h}$. The crude mixture was separated by column chromatography on silica, using dichloromethane/tetrahydrofuran $(5: 1 \mathrm{v} / \mathrm{v})$ as eluant, to isolate $\mathbf{2 g}$ as a yellow oil ( $72 \%$ yield) with the following spectroscopic data: $\delta \mathrm{H}\left(\mathrm{CDCl}_{3}, 300 \mathrm{MHz}\right) 8.51(\mathrm{dd}, 1 \mathrm{H}$, $J=3.90,1.35 \mathrm{~Hz}) ; 7.91(\mathrm{dd}, 1 \mathrm{H}, J=8.25,1.35 \mathrm{~Hz}) ; 7.29$ $(\mathrm{dd}, 1 \mathrm{H}, J=8.25,3.90 \mathrm{~Hz}) ; 6.32(\mathrm{~d}, 1 \mathrm{H}, J=2.70 \mathrm{~Hz})$; $6.29+6.28(\mathrm{~d}+\mathrm{d}, \quad 1 \mathrm{H}, \quad J=2.70 \mathrm{~Hz}), 6.01(\mathrm{dd}, 1 \mathrm{H}$, $J=7.95,3.15 \mathrm{~Hz}) ; 3.88(\mathrm{~s}, 3 \mathrm{H}) ; 3.64(\mathrm{~m}, 1 \mathrm{H}) ; 3.41(\mathrm{~m}$, $1 \mathrm{H}) ; 3.32(\mathrm{~d}, 1 \mathrm{H}, J=4.50 \mathrm{~Hz}) ; 3.01(\mathrm{~m}, 1 \mathrm{H}) ; 2.12(\mathrm{~m}, 1 \mathrm{H})$; $1.89(\mathrm{~m}, 1 \mathrm{H}) ; 1.71-1.34(\mathrm{~m}, 16 \mathrm{H}) ; 1.30(\mathrm{~d}, 3 \mathrm{H}$, $J=6.60 \mathrm{~Hz}) ; 1.01(\mathrm{~d}, 3 \mathrm{H}, J=6.90 \mathrm{~Hz}) ; 0.89(\mathrm{~d}, 3 \mathrm{H}$, $J=6.30 \mathrm{~Hz}) . \delta \mathrm{C}\left(\mathrm{CDCl}_{3}, 75 \mathrm{MHz}\right) 174.3 ; 174.2 ; 159.5$; $159.4 ; 145.1 ; 145.0 ; 144.3 ; 144.2 ; 135.4 ; 134.7 ; 129.9 ; 121.8$; $96.8 ; 96.7 ; 91.6 ; 80.9 ; 80.8 ; 77.3 ; 62.3 ; 55.2 ; 47.9 ; 47.5 ; 41.0$ $40.9 ; 40.2 ; 40.1 ; 38.2 ; 38.1 ; 34.0 ; 30.3 ; 29.5 ; 29.4 ; 29.3 ; 29.2$ $26.2 ; 26.1 ; 25.6 ; 22.5 ; 22.4 ; 22.1 ; 21.9 ; 20.7 ; 20.6 ; 19.3 ; 19.2$ $17.1 ; 17.0 . \mathrm{m} / \mathrm{z}\left(\mathrm{MW}_{\text {monoisotopic }}, \mathrm{M}^{+}\right)=452.3847$ (Calcd, 452.3151).

19. Pneumocystis carinii were obtained from chronically immunosuppressed rats housed under barrier conditions at the Cincinnati VA Medical Center (VAMC) and inoculated intratracheally with $P$. carinii. $P$. carinii were extracted and purified from the lungs of rats after 8-12 weeks of immunosuppression, enumerated, cryopreserved, and stored in liquid nitrogen. Typically, infected rat lungs yield up to $2 \times 10^{10}$ organism nuclei with the vast majority (about 95\%) of the life cycle forms present as trophic forms with the remainder (about 5\%) being composed of cysts. P. carinii preparations were evaluated for microbial contamination, ATP content, karyotype, and host cell content prior to use in the ATP assay. Each concentration of every compound is assayed in triplicate wells and the results expressed as the average relative light units. Triplicate runs for each compound concentration are performed using different organism isolation batches.

20. Cushion, M. T.; Chen, F.; Kloepfer, N. Antimicrob. Agents Chemother. 1997, 41, 379.

21. Van den Eynde, J. J.; Mayence, A.; Huang, T. L.; Collins, M. S.; Rebholz, S.; Walzer, P. D.; Cushion, M. T. Bioorg. Med. Chem. Lett. 2004, 14, 4545.

22. Shenai, B. R.; Lee, B. J.; Alvarez-Hernandez, A.; Chong, P. Y.; Emal, C. D.; Neitz, R. J.; Roush, W. R.; Rosenthal, P. J. Antimicrob. Agents Chemother. 2003, 47, 154.

23. Walzer, P. D.; Foy, J.; Steele, P.; White, M. Antimicrob. Agents Chemother. 1992, 36, 1943.

24. Portela, M. J.; Moreira, R.; Valente, E.; Constantino, L.; Iley, J.; Pinto, J.; Rosa, R.; Cravo, P.; do Rosário, V. E. Pharm. Res. 1999, 16, 949. 